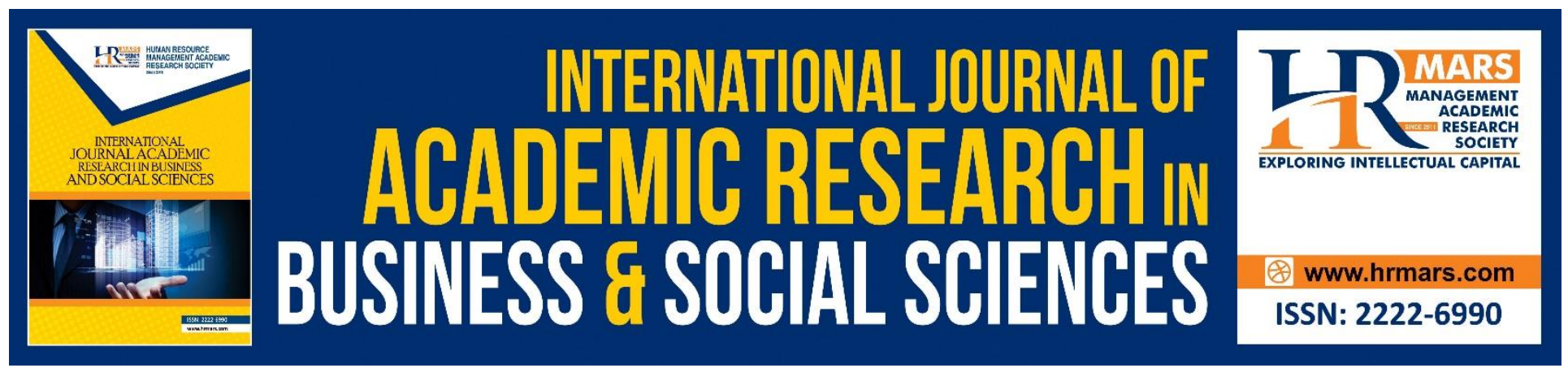

\title{
Factors Influencing Transfer of Training among Employees in Telekom Malaysia
}

Maimunah Mohd Shah, Nur Haziqah Md Hanafi, Idaya Husna Mohd, Mohd Shamim Che Hariri, Shezreen Dalina Rusdi

To Link this Article: http://dx.doi.org/10.6007/IJARBSS/v9-i6/6056

DOI: 10.6007/IJARBSS/v9-i6/6056

Received: 12 April 2019, Revised: 13 May 2019, Accepted: 01 June 2019

Published Online: 30 June 2019

In-Text Citation: (Shah, Hanafi, Mohd, Hariri, \& Rusdi, 2019)

To Cite this Article: Shah, M. M., Hanafi, N. H. M., Mohd, I. H., Hariri, M. S. C., \& Rusdi, S. D. (2019). Factors Influencing Transfer of Training among Employees in Telekom Malaysia. International Journal of Academic Research in Business and Social Sciences, 9(6), 939-950.

Copyright: (C) 2019 The Author(s)

Published by Human Resource Management Academic Research Society (www.hrmars.com)

This article is published under the Creative Commons Attribution (CC BY 4.0) license. Anyone may reproduce, distribute, translate and create derivative works of this article (for both commercial and non-commercial purposes), subject to full attribution to the original publication and authors. The full terms of this license may be seen

at: http://creativecommons.org/licences/by/4.0/legalcode

$$
\text { Vol. 9, No. 6, 2019, Pg. } 939-950
$$

Full Terms \& Conditions of access and use can be found at http://hrmars.com/index.php/pages/detail/publication-ethics 


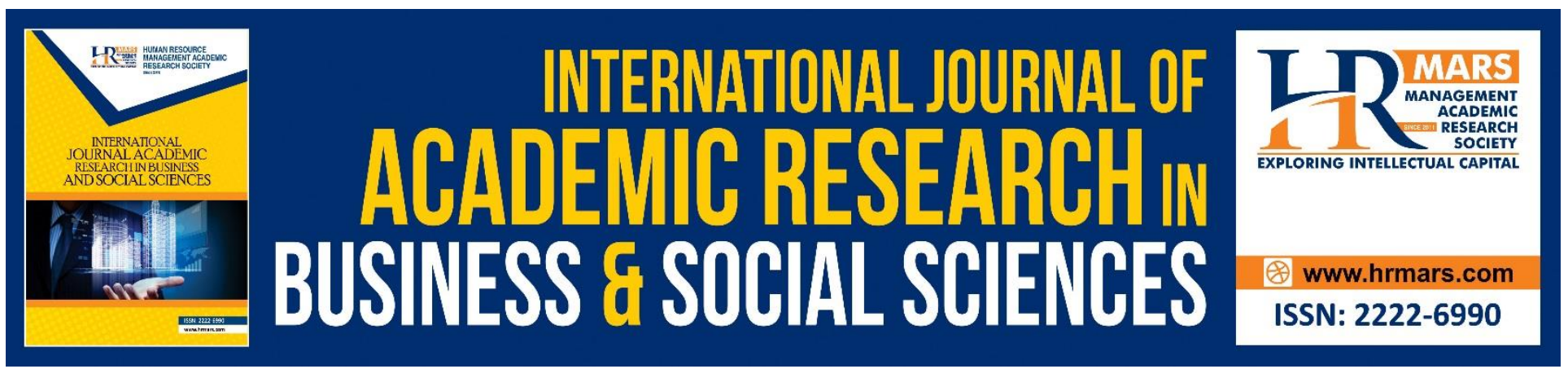

\title{
Factors Influencing Transfer of Training among Employees in Telekom Malaysia
}

\author{
Maimunah Mohd Shah, Nur Haziqah Md Hanafi, Idaya Husna Mohd \\ Mohd Shamim Che Hariri, Shezreen Dalina Rusdi
}

Faculty of Business and Management, Universiti Teknologi MARA, UiTM Selangor, Malaysia.

\begin{abstract}
The main aim of the study is to investigate the relationship between factors that influence transfer of training among employees in Telekom Malaysia. Investment of time, efforts and money becomes returns and benefits to organization that provide training to employees. Past study reported that employees fail to transfer knowledge or what they have learned during training. A low motivation can affect the effectiveness of training transfer. Therefore, 148 participants who had undergone training were involved in the study. The questionnaire was used to collect data and $100 \%$ returned questionnaires were analyzed using SPSS. The results reveal that $62.5 \%$ of the variance in the transfer of training is explained by support, training design and motivation. Further discussion is shared in the article.
\end{abstract}

Keywords: Transfer of Training, Support, Training Design, Motivation

\section{Introduction}

Training is some form of investment to build effective employees. Organization on the one hand provides training to employees so that the employees in return might be able to upgrade their sets of knowledge and also their skills. However, the bad news in all of this is that organization will suffer tremendous losses from the investment decision when employees that they have nurtured and trained decide to leave the organization and use their newly acquired skills in another organization. This would also represent a massive loss of investment/capital on the part of the organization that could have been better used in other areas of the organization. This study will try to deal with the extent of effectiveness of employees in transferring back the training that they'd gained/attended back at their workplace depends namely on three important factors. These identified factors are in essence; support, training design and also motivation.

Support from management, peers and supervisors can and would lead to an amplification on the efficacy of transfer of training and this is especially true for moments that would include; before, during and after training to the employees (Qurat-Ul-Ain, Arabella \& Raza, 2017). A study that is done in terms of transfer of training among employees is particularly important in ensuring the overall effectiveness of and organization's employees to apply both the acquisition of not only knowledge but 
would also include skills. It is therefore very intriguing to say the least for one to be able to identify the key factors that can and would ultimately improve the overall transfer of training. By doing this, the organization should be able to focus on the main problem. The main problem would be to identify on those that may lead to the significant decrease in the effectiveness capacity of transfer of training among employees.

Effective transfer of training on the one hand could provide a platform in giving the organization ample returns and benefits from its rigorous investments in the form of time, efforts and money as well. However, it is sad to note that participants often fail in a conundrum whereby they often times fail to optimally transfer back what they have learned at work. Employees who do not practice what they have learned or taught after the training has ended are categorically considered to be as ineffective (Nik Nadian, Abdul Rahim \& Salhah, 2015). Meanwhile, employees perceive the organization that they work for to be not supportive and acknowledging of their contributions might not put in any effort towards the usefulness of transfer of training (Tassanee, Yoshi \& Kriengkrai, 2013). Lack of appreciation, reward and moral support are often times considered to be the main cause in avert behavior among employees in the proper quest to deliver and apply the training into their work and tasks.

The variables that were studied for this research were based primarily on two notable studies which had chosen to focus exclusively on transfer of training (Ismail, Ng Kueh, Yusof, Ainon, Rizal \& Nurshahira, 2015). It is worth to jot down that support from supervisors, peers and management are very important elements or precursors to ignite and kick start not only motivation but also confidence of employees in learning and transferring training effectively. Supervisors could and should play a proper role as to properly effectively not only guide but also to instruct their employees and subordinates to keep up with training and also work. Peers at the workplace tend to spend most of their time together rather than spending their time with their supervisors while at the office.

Training design must not only be viewed as interesting and attractive but should also be matched and tied to the overall capability of the employees at large. This in turn would lead to a specific situation whereby the employees would be more interested and eager to participate and join the training. If the employees feel that by attending the training that they are then able to learn new knowledge continuously whereby the training is also viewed as something that is fulfilling their needs and be able to help them in encountering difficulties at work, then they would obviously join and take part. The net result at the end of the day towards the organization would be that it would have employees that will then become not only more efficient but also employees that are able to increase the overall effectiveness of transfer of training.

The last important facet in all of this is motivation. It is a peripheral component where without motivation, employees would in turn will not have any desire and interest within themselves to learn and to transfer all the useful training that they were supposed to picked up into their job or main responsibilities. It is very useful to note however that motivation of the organization's employees can and could be increased though means such as; by rewarding them with proper due recognition and also advancements throughout their career. Finally, top management should never ever neglect but instead must continuously focus to encourage and also appreciate their employees' effort to learn something new and to also apply knowledge that were 
INTERNATIONAL JOURNAL OF ACADEMIC RESEARCH IN BUSINESS AND SOCIAL SCIENCES Vol. 9, No. 6, June, 2019, E-ISSN: 2222-6990 @ 2019 HRMARS

obtained from the many trainings that they have attended towards their work. Therefore, the objective of this particular study is to sufficiently analyze all the factors that are deemed to be influencing transfer of training among employees of Telekom Malaysia.

\section{Literature Review}

Tassanee, Yoshi \& Kriengkrai (2013) had claimed that the type of support providers were namely supervisors and peer support but interesting to note that there are still some gaps left opened that were left within that particular empirical study. The gaps are namely attributed in concern to the extent of organizational support. In the opinion of Qurat-Ul-Ain et al., (2017), Arabella \& Raza. However, peer support is actually classed as the extent to which employees or workers of a particular organization reinforces and actively supports the application of learning on the job through factors such as like; goal setting, assistance and also positive feedback. Supervisors can play an active role by giving a hand and helping their employees to achieve this. Supervisors and do this in manners such as providing a reduced workload and not overwhelming employees with too much at one point in time. Supervisors also has to understand that work has to be spread out evenly over a period of time and this is done in particular so that trainees can have all the time that they require to get the job done and also due to the resounding need to overall plan in executing the application of their newly acquired skills (Qurat-Ul-Ain et al., (2017). Moving on, referring and looking towards findings that is also shared by Vasiliki \& Maria (2013), peers' and supervisors' support is viewed through the lenses as an important variable that seems to be highly correlated with the transfer of training. In fact, Khin \& Sujinda (2014) had actually taken the time to suggest and imply that there was in evidence a particular growing need to not only actively but continuously as well to encourage and instill within an organization's employees the actual needs to apply their sets of knowledge, skills and their abilities and that there is to be an active support platform. Support platforms such as feedbacks are required to be given out directly after training in the real workplace setting/environment. Supervisors could also take steps to encourage their employees by not only helping their subordinates but they could also be doing this by taking precious time in understanding the difficulties and major concerns that are faced by their subordinates in applying the things that had learned in training towards their job. In fact, supervisors should also be seen to facilitate and guide their employees. This is critical as this would then ensure that jobs that are handed out are implemented and executed using not only the right method but the right approach involving information and skills that were gained from any given training at any point in time.

Motivation that are industriously given out by organizations to their employees can also heighten and raise the overall interest of employees to actually deploy and use all their skills and knowledge at the workplace. Besides that, actively giving out motivation would also mean that employees continue to dedicate themselves to the organization for the long haul. Nik Nadian, Abdul Rahim, \& Salhah (2015) and Tonhäuser et al., (2016) confirmed that there seems to be positive influences in regards to matters pertaining to social support from colleagues and also from supervisors and this is then proven to be particularly true in regards to the role that is played by feedback. Based on the study by Seema (2017), it was discovered that employees need active encouragement and also support simply due to the fact that the transfer of new behavior and skills 
INTERNATIONAL JOURNAL OF ACADEMIC RESEARCH IN BUSINESS AND SOCIAL SCIENCES Vol. 9, No. 6, June, 2019, E-ISSN: 2222-6990 @ 2019 HRMARS

that were acquired in training to employees of any organization is alarmingly difficult to achieve without the proper support of supervision. It is then without any doubt that colleagues therefore have to mutually assist and help themselves out if there are found to be any such difficulty at work with what has been learned and taught (Nik Nadian et al., (2015).

Training Design meanwhile refers to the principle of not only learning but also training content as well. This then also takes into account the objectives, materials used and also content structures of the said training. Notable important elements that are related to training success would oftentimes include those such as; training design, the quality of instruction and lastly the content of training that will be delivered to the trainees (Nadian et al., 2015). The overall design of any particular training would require the most accurate and relevant information about the job so that it would then in the end play a role in helping to identify learning objectives and relevancy of training contents with actual employees' job responsibilities (Nik Sarina, Wan Abd Aziz, \& Ibrahim, 2016) According to Mohamad (2017), the contents of the training, learning principles and arrangement of learning activities seems to point and indicate that there is a direct and significant relationship with the transfer of training. Furthermore, according to Ragini et al., (2017), it is claimed that the training design element was in fact affirmed to be positively influencing transfer of training. The next set of results by research which were based on work done by Yaser et al., (2017) had indicated that dimensions such as need assessment, goal setting, considering the time required to do the job and content relevance had seemingly significantly affected the transfer of training within the training design itself. The organization should take note and should therefore maintain a momentum in their effort to continuously improve the training design and along with it goals that are consistent and parallel which go hand in hand with the overall needs of employees.

Motivation is a critical construct because it is a type and form of the following; involvement, recognition and a reward mechanism to the human resources. This is as a matter of fact is a basic building block for any organization and it is often times viewed or heralded as a fundamental aspect for any organization (Saeed, Wan Shakizah \& Mohd Faizal, 2017). Motivation is positively viewed as an internal generating force that tends to control and dictate our work (Pollitt \& Oldfield, 2017). Trainees' motivation to learn and transfer positively predicts the output of training transfer (Melody Ling \& Danny, 2014). Christian \& Simone (2017) on the other hand strongly support the idea that motivational aspects seems to play an important and integral role in the transfer of training. According to Mohamad (2017), the transfer of training seems to have a direct significant relationship with the motivation of the trainees with a value of $(r=0.405)$ which is considered to be having a medium relationship with transfer of training. In addition to this, motivation to transfer is significantly related to transfer of training with readings of $\left(R^{2}=0.137, \beta=0.37 .5, p<.001\right)$ Kamran \& Ghulam (2015) and Ana-Inés et al., (2014) meanwhile indicate that job-improvement motivation to participate in this type of training is a direct predictor of transfer of learning. Theoretically, any organizations on the face of this earth that has its sights locked on in improving the transfer of training should therefore primarily set its sight to focus on enhancing the overall participants' motivation to transfer (Christian \& Simone, 2017). Seema (2017) suggested that if more amount of attention were to be given to training motivation, more transfer will be assured of and this notable 
point has actually been proven within the study itself. It had revealed that transfer motivation has significantly affected transfer of training.

Transfer of Training is then defined as the degree to which trainees actually apply the following; on the job the knowledge, skills, behavior and attitudes they had willfully gained by attending the training. Besides that, transfer of training is also commonly defined as the use of trained knowledge and skill towards the job (Burke \& Hutchins, 2007). Transfer of training can also be influenced by some external factors namely such as; support, training design and also motivation of the said employees. Transfer of training is an important and pertinent issue that has been commonly and is continually addressed by many Human Resource Development (HRD) scholars and professionals alike in the past and present times. Transfer as an innovation actually refers to people's ability to learn new skills and the gaining of new knowledge in order to understand their environment in a different way. Ana-Inés et al. (2014] meanwhile state that only 21 percent of organizations that were interested to survey had assessed the level of transfer of training of their employees.

In summary, organizations should at all times be able to determine and also establish the usefulness and benefits of the training to their employees and organizations. It is therefore sad to note such a waste occurring whereby employees that have attended trainings, when they do not apply and use new knowledge that they have obtained for a period of six months onwards, the knowledge, skills and attitude that were acquired and picked up by them during the training would later be forgotten by them (Nik Nadian et al., 2015).

Support from supervisors, peers and management are very integral and important elements that should often times be deployed and showcased to ignite not only the motivation but also to instill a sense of confidence to the trainees in striving to learn and also transfer training effectively. They can then proceed to be the role model in giving out proper guidance and worthy instructions to trainees after the training. It has also been observed that supervisors would often times become the main source for the employees to refer to regarding any problems and as a form of insurance in the effort to ensure themselves not only that they are on the right track but also as a means to keep up with the training itself and work. It is also to be noted that peers are the closest form of companionship at the office and that peers are spending time among themselves more than with their supervisors.

\section{Hypotheses Development}

Based on the literature review, there were three hypotheses developed in this study. $\mathrm{H} 1$ There is a significant relationship between support and transfer of training.

$\mathrm{H} 2$ There is a significant relationship between training design and transfer of training.

H3 There is a significant relationship between motivation and transfer of training.

\section{Research Methodology}

The population in the study had consisted of a grand total of 240 employees who at that point in time were servicing the Group Procurement Department of Telekom Malaysia in Kuala Lumpur. Out of these 240 employees which had made up the population of this study, a short list was then drawn up in an attempt to identify employees who had attended training in the past. After this was done 
and those employees that had attended training were successfully identified, those whose names were shortlisted were then approached and asked to willingly participate in this study. Those that had agreed and given their agreement to participate in turn later became the sample size of this study. The final figure that had willingly participated stood at 148 employees out of the overall 240 employees which was the population of the study. In other words roughly $62 \%$ of the population had therefore participated in the study. A simple random sampling method was selected to be used in the quest to distribute the questionnaires. It's worth mentioning that before the actual questionnaire, there was also a cover letter before the actual questionnaire and this was done as an attempt to help guide the respondents or help the respondents in their attempt to answer the various items within the questionnaire. After the questionnaires were distributed, the next step of collecting the questionnaires to obtain the data within them were aided successfully by the same three representatives who had initially helped during the distribution phase of the said 148 questionnaires. It should be stressed that an established questionnaire were used. The usage of an established questionnaire was opted in order to guarantee the validity and reliability of the questionnaire used. The questionnaire had a Cronbach's Alpha value that were all above a 0.7 value for all the variables it had set out to measure. All items within the variables were measured using a standard 5 point Likert scale. This study then proceeded to run a standard Pearson correlation coefficient and multiple regression test. These tests were conducted to analyze and also to further scrutinize the data further.

\section{Findings and Data Analysis}

A final analysis was done based on 148 respondents in the study. Based on the cross-tabulation results on the demographic profile, it was discovered that the majority of the respondents are female and were aged between $31-35$ years old. Most of them were also married. In regards to their level of education, a majority of them had diploma and bachelor degrees respectively. It is very interesting to note that most of the respondents have been working for the company for a period of between 610 years in the organization. Referring to their positions in the department, a substantial majority of the said respondents were assuming a role at an executive level. The normality of the data was then proceeded to be checked through Kolmogorov-Smirnov's table. Since the p-value that was subsequently obtained is of a value that is more than $0.05(0.200)$, this then had further indicated that the data is therefore normal.

There were three hypotheses in the study. $\mathrm{H} 1$ : There is a significant relationship between motivation and transfer of training. $\mathrm{H} 2$ : There is a significant relationship between training design and transfer of training.

H3: There is a significant relationship between support and transfer of training.

Results of the correlational analysis in Table 1 seems to indicate that there are positive relationships between all the stated factor variables and transfer of training. The r-values are within 0-1 and the $\mathrm{p}$-value is less than 0.05 . 
INTERNATIONAL JOURNAL OF ACADEMIC RESEARCH IN BUSINESS AND SOCIAL SCIENCES Vol. 9, No. 6, June, 2019, E-ISSN: 2222-6990 @ 2019 HRMARS

Therefore, it can be safely concluded that there are indeed positive relationships between motivation and transfer of training $(\mathrm{H} 1)$, training design and transfer of training $(\mathrm{H} 2)$, support and transfer of training $(\mathrm{H} 3)$.

Table 1: Correlation Analysis ( $\mathrm{N}=148)$

A multiple linear regression test was also conducted and this was done in order to find the variable in the transfer of training. Based on the Model Summary, Table 2 indicates and points to the fact that all independent variables (support, training design and motivation) would explain $62.5 \%$ of the variance in the transfer of training. However, the rest of it at $37.5 \%$ of the variance is to be explained by other variables other than the ones within the context of this research.

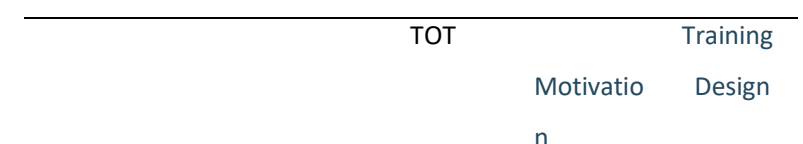

\begin{tabular}{|l|r|r|r|r|}
\hline $\begin{array}{c}\text { Mod } \\
\text { el }\end{array}$ & $R$ & $\begin{array}{c}R \\
\text { Square }\end{array}$ & $\begin{array}{c}\text { Adjuste } \\
\text { d R } \\
\text { Square }\end{array}$ & $\begin{array}{c}\text { Std. Error } \\
\text { of the } \\
\text { Estimate }\end{array}$ \\
\hline 1 & $.791^{\text {a }}$ & .625 & .617 & 2.5 \\
& & & & 64 \\
\end{tabular}

\begin{tabular}{|c|c|c|c|}
\hline Motivation & $\begin{array}{c}\text { r- } \\
\text { value }\end{array}$ & $.788 * *$ & \\
\hline Training & $r-$ & $.545^{* *}$ & $.630^{* *}$ \\
\hline Design & value & & \\
\hline Support & $\begin{array}{c}\text { r- } \\
\text { value }\end{array}$ & $.540 * *$ & $.635^{* *}$ \\
\hline
\end{tabular}

Table 2: Model Summary

After the results for multiple regression were obtained, which is as illustrated in Table 2, it is confirmed and established that motivation is indeed significantly influencing the transfer of training. In other words, employees need to be in a motivated state of mind before the actual act of transfer of training can be effective. Transfer of training is also indeed influenced by motivation which seems to mean that when employees are motivated, only then the transfer of training will be effective. Therefore, it can be safe to conclude that motivation factor is the number 1 factor which affects the most towards the transfer of training rather than training design factor and support factor. Motivation is viewed as a key factor in helping employees to improve the overall effectiveness of transfer of training. Unfortunately, it was also discovered that employees with low motivational levels tend to have or showcase a lesser interest and overall desire to transfer knowledge in their job. As a result of this rather sad phenomena, these said employees would then proceed to achieve low performance levels which would subsequently mean they are unworthy in attending training. However, organizations can take proper steps in order to increase motivation through actively rewarding compensation and benefits. By doing and implementing this simple step, employees would then feel and sense that they are being valued and that they are indeed important to the 
organization. A warm and fuzzy feeling of belonging and appreciated would also make employees to be more active on the job and willing to learn and also actively picking up new knowledge. At the end of it all, this would then result in an improvement in the employees overall performance in the workplace.

\section{Conclusion}

It seems that the organization needs to implement and deploy some alternative forms of methods if it aims to increase the overall effectiveness of transfer of training of their employees. The organization should actively seek out and identify some of the main causes that would lead to a decreasing in effectiveness of transfer of training and work out on the probable solutions to overcome the potential problems that would be coming in the future. It is therefore posited that in order to bring productivity and motivation to the employees, the organization can and should provide a proper reward career development and recognition acknowledgements if their employees are able to achieve a high performance in applying what was picked up during the training. In addition to this, the training design has to be viewed as attractive and also interesting as to actively encourage the employees to actually attend the training. Subsequently, the motivation level of employees should increase and as a result they would then proceed to utilize or deploy the knowledge and skills they've gathered and learned from the training at the actual workplace. In the end, the organization can gain and secure benefits in terms of cost and time and proceed to reap gains on the return from the investment in providing the training for the employees in the first place.

It is also noteworthy to mention that motivation is a cornerstone or a key factor in helping employees to improve their effectiveness of transfer of training. However, it is also sad to note that employees with low motivation levels have lesser interest and desire to transfer the training into their job as opposed to their counterparts who have a higher level of motivation. As a result, these group of employees would continue to portray and achieve low levels of performance and that they are unworthy of attending the training in the first place. Organizations can take steps to increase the motivation levels of their employees by actively giving and reviewing the compensation and benefits of their employees. This is done as to make their employees feel that they are highly valued and also important to the organization as a whole. The feeling of belonging and appreciation in the end make these employees be more active, willing to take part and also willing to learn new knowledge to improve their job performances which at the same time would improve the organization's position as well.

It is therefore suggested that organizations adopt the usage of Kirk Patrick's Training Evaluation Model to monitor and observe the overall degree of transfer of training not only before training but instead to also monitor during and after the training as well. Kirkpatrick \& Partners (1959) had suggested that there actually four levels of stages to determine the effectiveness and impact of employees training to themselves as well as the organization itself. The first stage is the reaction of the employees about the training programs. This stage should focus on the satisfaction of the training programs and whether or not they are satisfied with the instructors, the topic, the material, its presentation, and the venue. Reaction sheets or feedback survey should be used as a 
measurement tool in obtaining trainees" feedback regarding the training program itself. Their opinions can then be used to improve future upcoming training programs. Next stage is learning. This level is to measure the employees' gain of learning from the training. It will further indicate the degree of acquired knowledge, skills, attitude, confidence and commitment of the employees based on their involvement in the training. The pre and post training test can be used to measure the increase in overall knowledge or skills of employees. Besides that, the management could also use a controlled group to compare the trainee's performance. Therefore, the level of reaction and learning will be used to measure the quality of training program that will be designed and delivered.

It is very important for the employees to transfer the training that were obtained to their job because it would then lead to better performances which would ultimately mean the organization achieves its goals and maximizes its return. To determine the behavior stage, the management should make observations regarding their employees' behavior over a period of time. Finally, at the last stage is result. This stage is to finalize the results of training. It will give an indication on the final outcomes of whether the training actually benefits the employees and organization or not. A model used by Kirkpatrick \& Partners (1959) could be used to relate the effectiveness of transfer of training as an overall process that can be used to ensure not only the continuous improvement but also the attention to factors that can influence the level of training transfer. The management could then make comparisons from the Key Performance Indicator (KPI) to establish the productivity and quality of work of their employees. Thus, the level of behavior would result in a more focused training effectiveness. Future researchers could lead and contribute to the improvement on how to actively improve the support and encouragement from the organization, training design and level of motivation of employees to transfer the training. Other than that, future researchers can and should consider other factors in their research on transfer of training. Notable factors that could be perused upon for future studies would be factors such as learning environment, communication and also assignment.

\section{Aknowledgement}

Thank you very much to Nur Haziqah Md Hanafi who has permitted the team members to work on this report. Thank you UiTM.

\section{Corresponding Author}

Maimunah Mohd Shah, Faculty of Business and Management, Universiti Teknologi MARA, UiTM Selangor, Malaysia.

Email: maimu697@puncakalam.uitm.edu.my

\section{References}

Ismail, A. Ng Kueh H., Yusof, I., Ainon, J. A. S., Rizal A. B., Nurshahira, I. (2015). Administrators" Roles in Training Programs and Training Transfer. Jurnal Dinamika Manajemen, Vol. 6, No. 1, pp: 2539. 
INTERNATIONAL JOURNAL OF ACADEMIC RESEARCH IN BUSINESS AND SOCIAL SCIENCES

Vol. 9, No. 6, June, 2019, E-ISSN: 2222-6990 @ 2019 HRMARS

Ana-Inés, R. D., José-Miguel, J. G, Manel, F. G, Ángel-Pío, G. S. (2014). Transfer of learning: Motivation, training design and learning-conducive work effects. European Journal of Training and Development, Vol. 38 Issue: 8, pp.728-744.

Burke, L. A. \& Hutchins, H. M. (2007). Training transfer: an integrative literature review. Human Resource Development Review, Vol. 6 No. 3, pp. 263-296.

Christian S. \& Simone K. (2017).Volition to transfer: mastering obstacles in training Transfer. Personnel Review, Vol. 46 Issue: 4, pp.809-823.

Saeed, E. I. Y., Wan Shakizah W. M. N., \& Mohd Faizal M. I. (2017). Factors Influencing Training Effectiveness: Evidence from Public Sector in Bahrain. Acta Universitatis Danubius, Vol 13, no 2.

Kamran, I. \& Ghulam, D. (2015). Impact of self-efficacy and retention on transfer of training: the mediating role of motivation to transfer. Journal of Management Development.

Marlar, K. M. \& Sujinda C. (2014). Work Environment Factors Influence on Transfer of Training in Myanmar. South East Asia Journal of Contemporary Business, Economics and Law, Vol. 4, Issue 1.

Kirkpatrick, D. L., \& Partners, K. (1959). Training evaluation model-the four levels of learning evaluation.

Mohamad, B. S. (2017). The Relationship among Trainees Characteristics, Training Design and Work Environment with Training Transfer. Malaysia Royal Custom Department.

Melody, Ling-Y. W. \& Danny, Y. C. L. (2014). Trainees' Characteristics in Training Transfer: The Relationship among Self-Efficacy, Motivation to Learn, Motivation to Transfer and Training Transfer. International Journal of Human Resource Studies, Vol. 4, No. 1.

Pollitt, K., \& Oldfield, J. (2017). Overcoming the odds: Exploring barriers and motivations for male trainee primary teachers. Teaching and Teacher Education, 62, 30-36.

Qurat-Ul-Ain Q., Arabella, B. \& Ali, R. T. (2017). Factor Affecting the Transfer of Training at the Workplace: Case study of SSGC Ltd, Pakistan. International Journal of Academic Research in Business and Social Sciences 2017, Vol. 7, No. 2.

Ragini, C., Piyali, G., Alka, R. \& Sanchita, K. (2017). Improving transfer of training with transfer design: Does supervisor support moderate the relationship? Journal of Workplace Learning, Vol. 29 Issue: 4, pp.268-285.

Seema, S. (2017). Trainee Characteristics and Transfer of Training: Effect of Supervisory Support (A Study of Public Managers in Nepal). Journal of Business and Management Research, Vol.2, No.1 \& 2, pp.1-13.

Tassanee H., Yoshi T. \& Kriengkrai T. (2013). Effects of Individual and Work Environment Characteristics on Training Effectiveness: Evidence from Skill Certification System for Automotive Industry in Thailand. International Business Research. Vol. 6, No. 12.

Tonhäuser, Cornelia; Büker \& Laura (2016). Determinants of transfer of training: A comprehensive literature review. International journal for research in vocational education and training, 2, S. 127-165.

Brinia, V., \& Efstathiou, M. (2013). Relationships between Factors affecting the Transfer of Vocational Safety Training in The Workplace: The Case Study of Aluminium of Greece. Journal of Technical Education and Training (JTET), 36, Vol. 5, No.2. 
INTERNATIONAL JOURNAL OF ACADEMIC RESEARCH IN BUSINESS AND SOCIAL SCIENCES

Vol. 9, No. 6, June, 2019, E-ISSN: 2222-6990 @ 2019 HRMARS

Yaser, S., Saeed, R., Yasamin, A. \& Khalil, G. (2017). An Examination of Factors Affecting Transfer of Training among Human Resources of Iranian Medical Science Universities. Indian Journal of Science and Technology, Vol 10(18). 